\title{
Insulin-like growth factor 1 prevents neuronal cell death and paraplegia in the rabbit model of spinal cord ischemia
}

\author{
Yoshihisa Nakao, MD \\ Hajime Otani, MD \\ Tadashi Yamamura, MD \\ Reiji Hattori, MD \\ Motohiko Osako, MD \\ Hiroji Imamura, MD
}

Objective: Insulin-like growth factor 1 has been shown to be cytoprotective against ischemia-reperfusion injury in various organs. However, spinal cord protection by insulin-like growth factor 1 has not been tested. We have therefore examined the effect of insulin-like growth factor 1 on neuronal cell death and motor function after spinal cord ischemia.

Methods: Japanese white rabbits were subjected to spinal cord ischemia by clamping the abdominal aorta for 15 minutes. Insulin-like growth factor $1(0.3 \mathrm{mg} / \mathrm{kg})$ at a dose equipotent to insulin $(0.3 \mathrm{IU} / \mathrm{kg})$ in lowering blood glucose level or the control (phosphate-buffered saline solution as a vehicle) was administered intravenously 30 minutes before the aortic clamp.

Results: Hind-limb motor function had recovered normally 48 hours after the operation in all the rabbits $(\mathrm{n}=8)$ treated with insulin-like growth factor 1 . In contrast, all the control-treated $(n=8)$ and all but one of the insulin-treated $(n=6)$ rabbits had deteriorated to paraplegia by 48 hours after the operation. Histopathologic sections in the involved spinal cord segment showed that a significantly $(P<.0001)$ greater number of motor neuron cells were preserved in the rabbits treated with insulin-like growth factor $1(17.9 \pm 4.8$ per section) than in those treated with the control $(8.0 \pm 2.1)$. Although insulin was equipotent to insulin-like growth factor 1 in preserving the number of motor neuron cells $(18.5 \pm 2.7)$, the percentage of motor neuron cells positive for terminal deoxynucleotidyltransferase-mediated deoxyuridine triphosphate-biotin nickend labeling were significantly $(P<.01)$ smaller in the rabbits treated with insulin-like growth factor $1(6.0 \pm 4.6)$ compared with those treated with the control $(54.6 \pm 33.8)$ and insulin $(26.2 \pm 11.7)$. Immunohistochemical studies revealed that insulin-like growth factor 1 increased expression of the antiapoptotic Bcl-xL protein and inhibited expression of the proapoptotic Bax protein in motor neuron cells 24 and 48 hours after the operation. In contrast, expression of only Bax was increased after the operation in other groups of rabbits subjected to spinal cord ischemia.

Conclusions: These results suggest that insulin-like growth factor 1, but not insulin with a conventional dose, protects motor neuron cells from ischemic spinal cord injury associated with differential regulation of Bcl-xL and Bax protein.

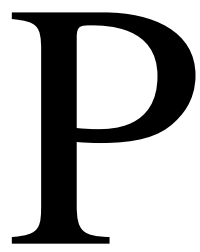

araplegia remains a major devastating complication after operations for thoracoabdominal aortic aneurysm. ${ }^{1,2}$ Strategies avoiding ischemic spinal cord injury have been a subject for extensive investigation. Because identification of the Adamkiewicz artery and its selective reconstruction are difficult in the majority of cases, mechanical and pharmacologic interventions have been attempted to reduce 
the incidence of perioperative paraplegia. However, despite numerous efforts, none of the procedures have been proven to be consistently effective in preventing paraplegia. ${ }^{3}$

The unique feature of ischemic spinal cord injury is the occurrence of delayed-onset paraplegia. The delayed-onset paraplegia can be induced after a relatively brief period of spinal cord ischemia in the rabbit model by crossclamping of the abdominal aorta. Studies have demonstrated progressive loss of motor neurons accompanied with a steady decline of motor function. ${ }^{4-6}$ More recently, it has been shown that the form of death in motor neuron cells subjected to spinal cord ischemia is not only necrosis but also apoptosis, ${ }^{7,8}$ which may be a mechanism of the delayed onset of neuronal cell death.

Although life and death of the cell is determined by a number of intracellular events, Bcl-2 family proteins play a pivotal role in the death regulatory process. Bax is involved in the induction phase of cell death, whereas Bcl-2 and Bcl$\mathrm{xL}$ are known to counteract the death-promoting action of Bax. ${ }^{9-11}$ A significant correlation between the level of Bcl-2 family proteins and the severity of infarction after ischemia has been reported in the heart and the brain. ${ }^{12-15}$ Thus, pharmacologic interventions that induce up-regulation of antiapoptotic Bcl-2 family proteins and down-regulation of proapoptotic Bcl-2 family proteins could represent a promising approach for prevention of paraplegia.

Insulin-like growth factor 1 (IGF-1) is a local effector of growth hormone and has a structural similarity to proinsulin and functional similarity to insulin. ${ }^{16,17}$ IGF-1 has been shown to provide cytoprotection against neuronal cells and myocytes subjected to ischemia and reperfusion. ${ }^{18,19}$ Recent studies indicate that $\mathrm{Bcl}-2$ family proteins may be effector molecules responsible for IGF-1-induced cytoprotection. ${ }^{20-22}$ Therefore, we have examined the effect of IGF-1 and insulin on motor functions and neuronal cell death after spinal cord ischemia in relation to the expression of $\mathrm{Bcl}-2$ family proteins.

\section{Materials and Methods Surgical Preparation}

Japanese white rabbits weighing 2.5 to $3.5 \mathrm{~kg}$ were anesthetized with $1.0 \%$ halothane and $99 \%$ oxygen. Animals were placed in the supine position and allowed to breath spontaneously without mechanical ventilation. A 24-gauge venous catheter was placed in the marginal ear vein, and cefamandole $(50 \mathrm{mg} / \mathrm{kg})$ was administered as a single dose. A 22-gauge arterial catheter was placed in the central ear artery. Arterial pressure and rectal temperature were monitored continuously. A heating pad was placed under the rabbit to maintain rectal temperature at $37^{\circ} \mathrm{C}$ to $38^{\circ} \mathrm{C}$. After the rabbit had been stabilized, a median laparotomy was performed. The abdominal aorta was dissected just caudal to the left renal artery and above the bifurcation of the aorta. After systemic anticoagulation with intravenous injection of heparin sulfate $(200 \mathrm{U} / \mathrm{kg})$, a 20gauge catheter was introduced over a guide wire from the right femoral artery to the abdominal aorta. The tip of the femoral artery catheter was placed $5 \mathrm{~mm}$ above the bifurcation of the aorta to monitor aortic arterial pressure of the clamped segment. Spinal cord ischemia was introduced by clamping of the aorta at 3 points, the abdominal aorta just caudal to the left renal artery, the posterior mesenteric artery, and the bifurcation of the aorta, for 15 minutes. The bifurcation of the aorta was clamped with a snare so as not to occlude the femoral artery catheter, and the other 2 points were crossclamped with surgical microclamps. The snare and the aortic crossclamps were removed after 15 minutes, and the abdomen was closed in 2 layers. After the operations, all the rabbits were returned to their cages and allowed free access to water and food. Animal care and experiments complied with the "Guide for the Care and Use of Laboratory Animals" prepared by the Institute of Laboratory Animal Resources, National Research Council, and published by the National Academy Press, revised 1996.

\section{Experimental Groups}

Eight rabbits received IGF-1 $(0.3 \mathrm{mg} / \mathrm{kg}), 6$ rabbits received insulin $(0.3 \mathrm{IU} / \mathrm{kg})$, and 8 rabbits received $1 \mathrm{~mL}$ of phosphatebuffered saline solution intravenously as the vehicle control 30 minutes before the aortic clamping. Five rabbits of the sham-operated group underwent laparotomy, and the aorta was dissected as described above without aortic clamping. IGF-1 was a generous gift from Fujisawa Pharmaceutical Co Ltd (Osaka, Japan). Insulin (human recombinant) was obtained from Wako Pure Chemical Industries Ltd (Osaka, Japan). The doses of IGF-1 and insulin used in the present study were determined according to the guidelines of clinical use of IGF-1 published by Fujisawa Pharmaceutical Co Ltd in 1995. The doses of IGF-1 and insulin were equipotent with respect to glucose metabolism, and increasing the doses 5 times resulted in lethal hypoglycemia in some animals.

\section{Neurologic Assessment}

Hind-limb motor function was scored at 6, 24, and 48 hours after the operation by using the modified Tarlov scale ${ }^{23}(0=$ no movement; 1 = slight movement; 2 = sits with assistance; $3=$ sits alone; 4 = weak hop; $5=$ normal hop). Two observers (one of whom was blinded to the experimental conditions) graded the neurologic status independently.

\section{Histopathologic Examination and Terminal Deoxynucleotidyltransferase-Mediated Deoxyuridine Triphosphate-Biotin Nick-End Labeling}

All rabbits underwent laparotomy 48 hours after the first operation. As soon as the abdominal aorta was clamped as described above, the animals were anesthetized with an intravenous injection of a lethal dose of sodium pentobarbital $(200 \mathrm{mg} / \mathrm{kg})$ and heparin sulfate $(200 \mathrm{U} / \mathrm{kg})$, and the spinal cord was perfusion fixed with $10 \%$ formaldehyde through the femoral artery catheter placed within the clamped aorta. The lumbar spinal cord was removed, fixed for 2 weeks in the same fixative, and embedded in paraffin. Transverse sections were cut to a thickness of $4 \mu \mathrm{m}$ at the level of L6. The sections were stained with hematoxylin and eosin for histopathologic observations. For quantification of the number of motor neuron cells, motor anterior horn cells were counted in 3 sections at a magnification of $400 \times$, and the values were averaged. 
TABLE 1 Effect of insulin-like factor-1 (IGF-1) and insulin on hind-limb motor function

\begin{tabular}{|c|c|c|c|c|c|c|c|c|c|}
\hline \multirow[b]{2}{*}{ Tarlov score } & \multicolumn{3}{|c|}{ Control (n = 8) } & \multicolumn{3}{|c|}{ IGF-1 ( $n=8)$} & \multicolumn{3}{|c|}{ Insulin (n = 6) } \\
\hline & $6 \mathrm{~h}$ & $24 \mathrm{~h}$ & $48 \mathrm{~h}$ & $6 h^{*}$ & $24 \mathrm{ht}$ & $48 \mathrm{ht}$ & $6 \mathrm{~h}$ & $24 \mathrm{~h}$ & $48 \mathrm{~h}$ \\
\hline 0 & 4 & 6 & 8 & 0 & 0 & 0 & 3 & 4 & 4 \\
\hline 1 & 1 & 2 & 0 & 0 & 0 & 0 & 2 & 0 & 0 \\
\hline 2 & 0 & 0 & 0 & 0 & 0 & 0 & 0 & 0 & 0 \\
\hline 3 & 0 & 0 & 0 & 0 & 0 & 0 & 0 & 0 & 0 \\
\hline 4 & 1 & 0 & 0 & 2 & 1 & 1 & 0 & 1 & 1 \\
\hline 5 & 2 & 0 & 0 & 6 & 7 & 7 & 1 & 1 & 1 \\
\hline
\end{tabular}

Hind-limb motor function was assessed by Tarlov score as described in the "Materials and methods."

${ }^{*} P>.05$ compared with control.

$\dagger P>.01$ compared with control.

The serial sections were analyzed for motor neuron cell apoptosis by using a terminal deoxynucleotidyltransferase-mediated deoxyuridine triphosphate-biotin nick-end labeling (TUNEL) method with Apop Tag (Oncor Inc, Gaithersburg, Md). TUNELpositive motor anterior horn cells were counted in 3 sections at a magnification of $200 \times$, and the percentage of TUNEL-positive motor neuron cells was calculated.

\section{Immunohistochemical Staining for Bcl-2 Family Proteins}

The sections were placed in a glass jar filled with $10 \mathrm{mmol} / \mathrm{L}$ citrate buffer ( $\mathrm{pH}$ 6.0) and exposed to a 500-W microwave for 5 minutes twice. The sections were incubated in absolute methanol containing $0.3 \%$ hydrogen peroxide for 30 minutes, and nonspecific binding was blocked with normal goat serum. The sections were then incubated overnight at $4^{\circ} \mathrm{C}$ with the primary antibodies (rabbit polyclonal anti-Bcl-2 antibodies, rabbit polyclonal anti-Bcl$\mathrm{xS} / \mathrm{L}$ antibodies, or rabbit polyclonal anti-Bax antibodies) at 1:20 dilution. These antibodies were obtained from Santa Cruz Biotechnology (Santa Cruz, Calif). Afterward, the slides were washed with phosphate-buffered saline solution and incubated with fluorescein isothiocyanate-conjugated or tetrarhodamine isothiocyanate-conjugated goat anti-rabbit $\mathrm{F}\left(\mathrm{ab}^{\prime}\right) 2$ immunoglobulin IgG (Zymed Laboratories, Inc, San Francisco, Calif) at a 1:100 dilution for 1 hour at room temperature. The fluorescence staining was visualized with confocal laser microscopy (Fluoview; Olympus, Tokyo, Japan) at a magnification of $600 \times$.

\section{Statistical Analysis}

Statistical analysis of the neurologic scores was performed with the nonparametric Mann-Whitney $U$ test. All other data are presented as means $\pm \mathrm{SD}$. One-way analysis of variance and the Scheffé multiple comparison test were used to compare the multigroup variables.

\section{Results}

\section{Blood Glucose Level}

Blood glucose levels immediately before injection of IGF-1 or insulin were not significantly different from those in the

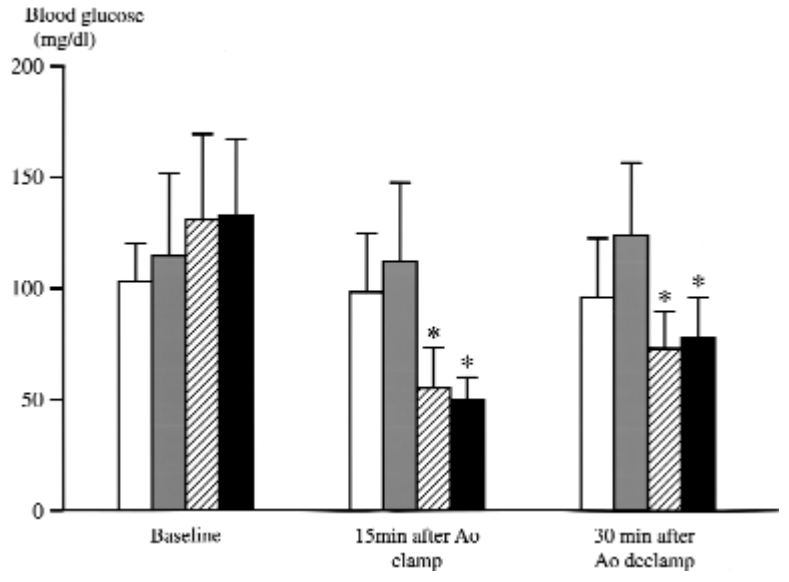

Figure 1. Blood glucose levels in the sham-operated ( $n=5$, open bars), control ( $n=8$, shaded bars), IGF-1-treated ( $n=8$, hatched bars), and insulin-treated ( $n=6$, filled bars) rabbits. ${ }^{*} P<.01$ compared with control rabbits. Ao, Aortic.

time-matched, sham-operated rabbits or the control rabbits (Figure 1). However, blood glucose levels were significantly lowered in the IGF-1-treated and insulin-treated rabbits compared with the sham-operated and control rabbits. The peak decline of blood glucose levels was observed at 15 minutes after aortic clamping in both the IGF-1-treated and insulin-treated rabbits. The magnitude of decline of blood glucose levels was similar between the IGF-1-treated and insulin-treated rabbits 15 minutes after aortic clamping and 30 minutes after aortic declamping.

\section{Neurologic Assessment}

The sham-operated rabbits showed no neurologic deficit during a 48-hour observation period. Paraplegia (score 0) developed in 4 of 8 rabbits in the control group within 6 hours after the operation (Table 1). The condition of the other 2 rabbits and the rest of the rabbits in the control group had deteriorated to paraplegia by 24 and 48 hours after the operation, respectively. In contrast, all the rabbits treated with IGF-1 maintained hind-limb motor function scores of 4 or 5 for 48 hours after the operation. Although 2 of 6 rabbits treated with insulin maintained hind-limb motor function scores of 4 or 5 for 48 hours after the operation, paraplegia developed within 24 hours after the operation in the other 4 rabbits. Consequently, the IGF-1 but not the insulin treatment significantly improved neurologic function at any given observation period compared with that of the control rabbits.

\section{Histopathologic Examination}

No sign of spinal cord damage was observed in hematoxylin and eosin-stained sections in the sham-operated rabbits (Figure 2, upper panel). However, in the control rabbits the 
Sham

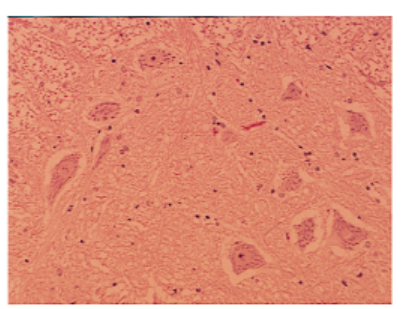

Control

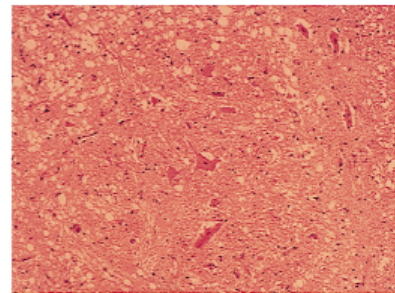

IGF-I

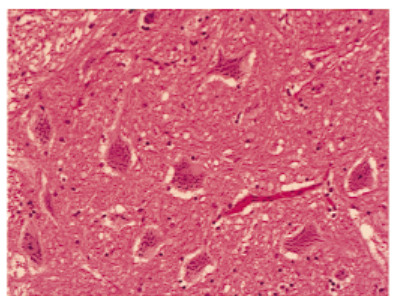

Insulin

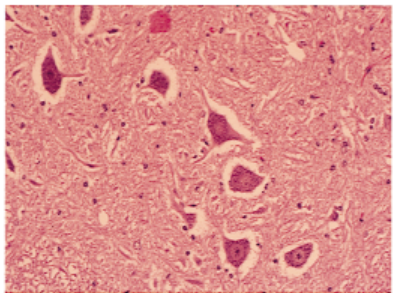

Motor neuron cells (Number/section)

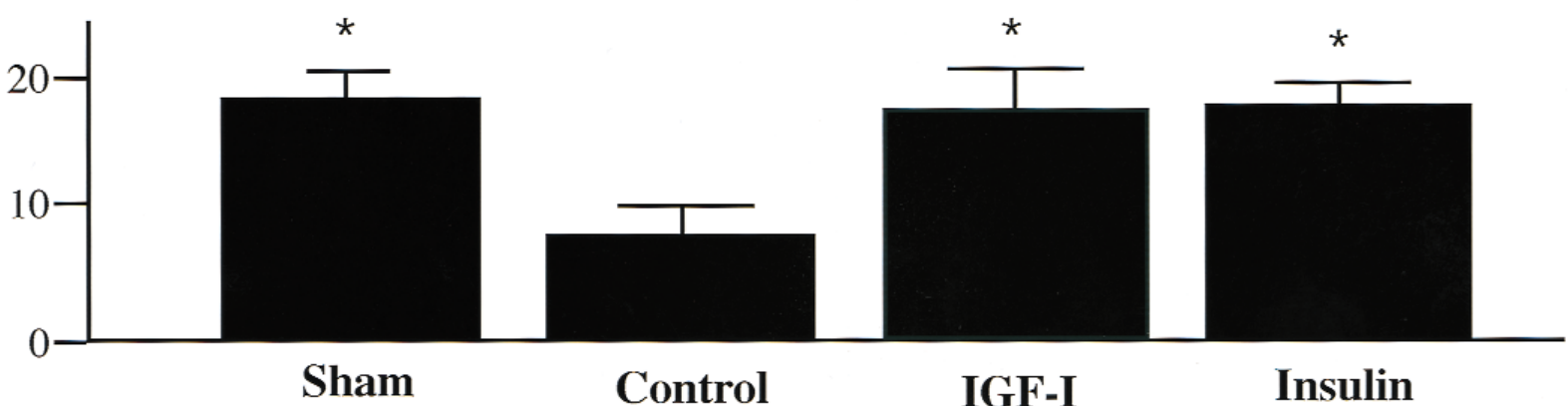

Figure 2. Hematoxylin and eosin staining of the spinal cord segment (L6) 48 hours after spinal cord ischemia (upper panel; original magnification $400 \times$ ). The number of motor neuron cells in the motor anterior horn per section (lower panel) is shown in the sham-operated group $(n=5)$, the control group $(n=8)$, the IGF-1-treated group $(n=8)$, and the insulin-treated group $(n=6) .{ }^{*} P<.0001$ compared with the control group.

segment that had been subjected to spinal cord ischemia showed severe neuronal damage, as evidenced by reduced numbers of motor neuron cells, disappearance of Nissl bodies and nuclei in the remaining motor neuron cells, and vacuolation of gray matter. In contrast, the rabbits treated with IGF-1 showed almost intact-looking light microscopic findings of the involved spinal cord segment. The rabbits treated with insulin showed microscopic abnormalities in the involved spinal cord segment similar to those observed in the control rabbits, although the number of motor neuron cells was preserved.

Quantitative analysis showed that the number of motor neuron cells in the involved spinal cord segment in the rabbits treated with IGF-1 and insulin was comparable with that in the sham-operated rabbits and was significantly $(P<$ .0001) greater than that in the control rabbits (Figure 2, lower panel).

\section{TUNEL staining}

Very few TUNEL-positive motor neuron cells were found in the motor anterior horn in the sham-operated rabbits (Figure 3 ). The percentage of TUNEL-positive motor neuron cells was markedly increased in the motor anterior horn of the involved spinal cord segment 48 hours after spinal cord ischemia in the control rabbits. In contrast, the percentage of TUNEL-positive motor neuron cells was significantly $(P<$ $.01)$ reduced by treatment with IGF-1. Although the insulin treatment tended $(P<.1)$ to inhibit the emergence of TUNEL-positive motor neuron cells compared with that in control-treated rabbits, this inhibition was incomplete, and IGF-1 was significantly $(P<.001)$ more effective in reducing the number of TUNEL-positive motor neuron cells than was insulin.

\section{Expression of Bcl-xL and Bax}

We examined whether IGF-1-induced inhibition of apoptosis is associated with enhanced expression of antiapoptotic Bcl-2 family proteins, attenuated expression of proapoptotic Bcl-2 family proteins, or both. We focused on Bcl-xL and Bax because these two proteins are known to play a pivotal role in neuronal development and neuronal cell death in postnatal life. ${ }^{24,25}$ Expressions of Bcl-xL and Bax in motor neuron cells was not immunohistochemically detectable in the sham-operated rabbits (Figure 4). However, expression 
Sham

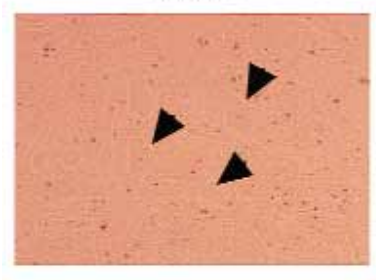

Control

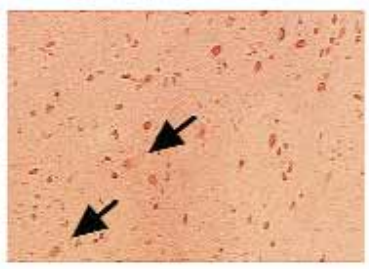

IGF-I

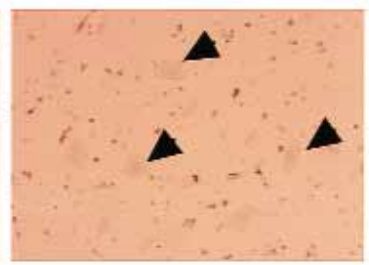

Insulin

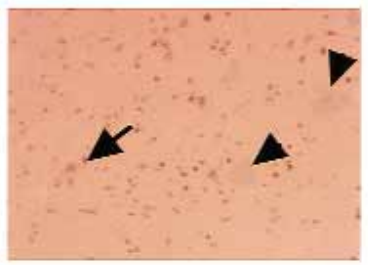

TUNEL-positive cells (\%)

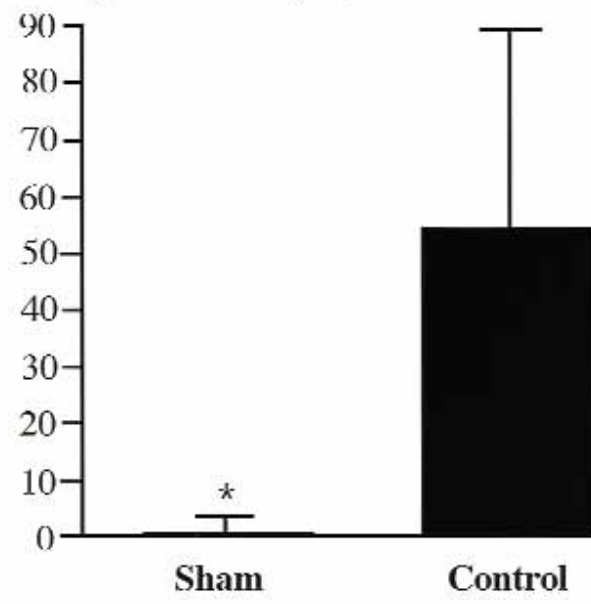

Sham

Control

Figure 3. TUNEL staining of the spinal cord segment (L6) 48 hours after spinal cord ischemia (upper panel; original magnification $200 \times$ ). Arrowhead, TUNEL-negative motor neuron cells; arrow, TUNEL-positive motor neuron cells. Percentage of TUNEL-positive motor neuron cells in the motor anterior horn (lower panel) is shown in the sham-operated group ( $n=5$ ), the control group $(n=8)$, the IGF-1-treated group ( $n=8)$, and the insulin-treated group $(\mathrm{n}=6)$. ${ }^{*} \boldsymbol{P}<.01$ compared with the control group. $+\boldsymbol{P}<.001$ compared with the IGF-1 group.

of only Bax was increased in the majority of motor neuron cells in the involved spinal cord segment in the control rabbits 24 and 48 hours after spinal cord ischemia. In contrast, expression of only Bcl-xL was increased in the majority of motor neuron cells in the involved spinal cord segment in the rabbits treated 24 and 48 hours after the operation with IGF-1. The insulin treatment modestly increased Bcl-xL and inhibited Bax expression 24 hours after spinal cord ischemia, but only Bax expression was elevated 48 hours after the operation. Bcl-2 was undetectable in motor neuron cells after any treatment modality (not shown). Similar results with respect to $\mathrm{Bcl}-\mathrm{xL}, \mathrm{Bax}$, and $\mathrm{Bcl}-2$ expressions were observed in all the rabbits of each experimental group.

\section{Discussion}

The present study provides the evidence for the first time that intravenous administration of IGF-1, but not insulin, was capable of preventing paraplegia after spinal cord ischemia. Development of paraplegia was associated with morphologic deterioration and the loss of motor neuron cells and the emergence of TUNEL-positive motor neuron cells in the spinal cord segment subjected to ischemia. The treatment with IGF-1 preserved hind-limb motor function, morphologic integrity, and the number of motor neuron cells and inhibited the emergence of TUNEL-positive motor neuron cells. In contrast, the insulin treatment was not effective in reversing the loss of hind-limb motor function. Although insulin preserved the number of motor neuron cells 48 hours after the operation at levels comparable with those of IGF1 , it failed to prevent morphologic deterioration and apoptosis of motor neuron cells. These findings suggest that the effect of insulin treatment was only to delay motor neuron cell death, and these cells ultimately died from apoptosis.

Although IGF-1 and insulin produce metabolically similar effects on the cells, the mechanism of cytoprotection is quite different. The doses of IGF-1 and insulin used in the present study were equipotent in reducing blood glucose levels, indicating that increased glucose metabolism is not a mechanism of IGF-1-induced spinal cord protection. Instead, IGF1-induced inhibition of motor neuron cell death was associated with an increase in antiapoptotic Bcl-xL expression and inhibition of proapoptotic Bax expression. Such a differential 


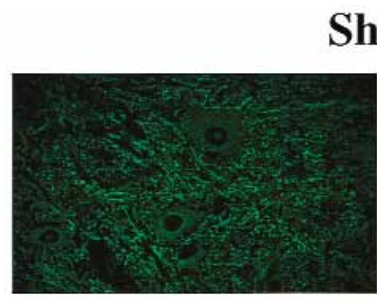

Sham
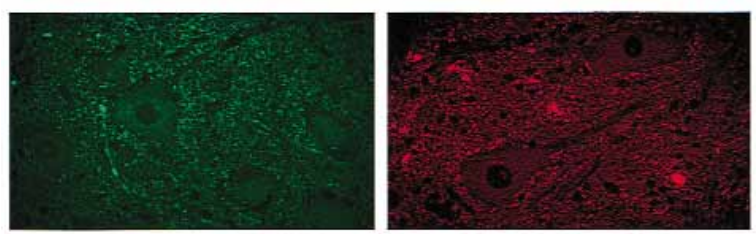

Control
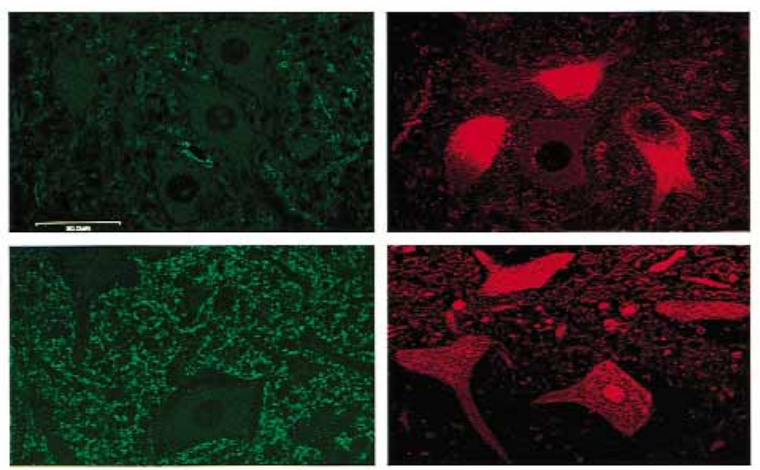

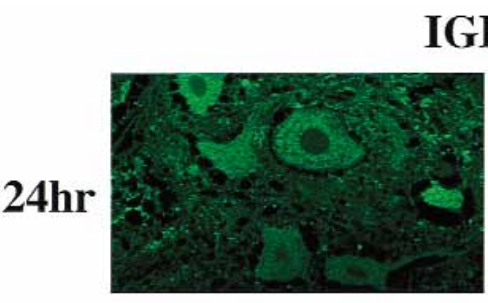

IGF-I

$48 \mathrm{hr}$
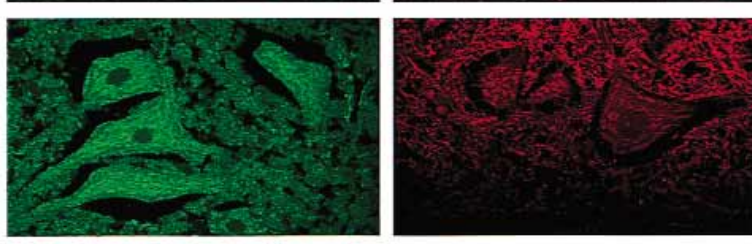

\section{Insulin}
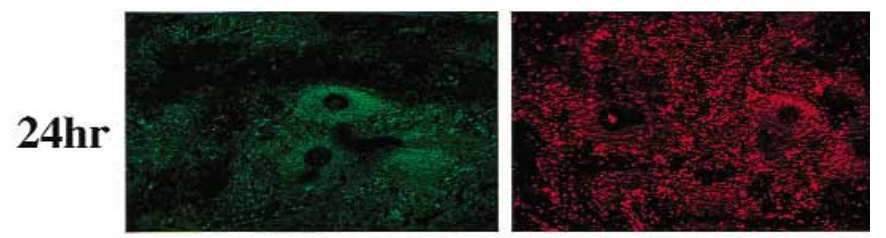

$48 \mathrm{hr}$
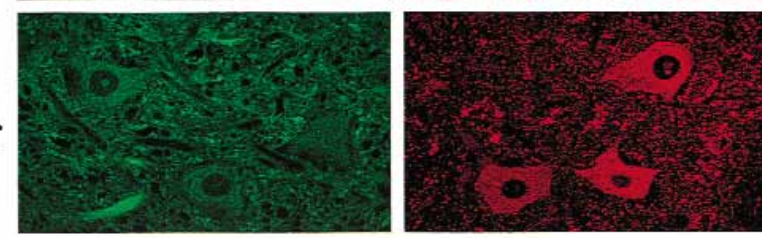

Figure 4. Immunohistochemical staining for Bcl-xL (green fluorescence) and Bax (red fluorescence) in the spinal cord segment (L6) 24 and 48 hours after spinal cord ischemia. The fluorescence staining was visualized with confocal laser microscopy at a magnification of $600 \times$. No appreciable expression of Bcl-xL and Bax was observed in motor neuron cells in the sham-operated rabbits. Expression of only Bax was increased in motor neuron cells in the control rabbits 24 and $\mathbf{4 8}$ hours after spinal cord ischemia. Treatment with IGF-1 increased expression of Bcl$\mathrm{xL}$ in motor neuron cells, with no appreciable expression of Bax 24 and 48 hours after spinal cord ischemia. Treatment with insulin modestly increased Bcl-xL and inhibited Bax expression 24 hours after spinal cord ischemia, but only Bax expression was elevated 48 hours after the operation.

regulation of Bcl-2 family proteins was not appreciable 48 hours after the operation in the insulin-treated rabbits. It is therefore suggested that differential regulation of Bcl-xL and Bax expressions may be involved in the antineuronal cell death effect of IGF-1. IGF-1 and insulin are known to provoke common intracellular signaling pathways leading to up-regulation of Bcl-xL and down-regulation of Bax. However, activation of this pathway by insulin should be much weaker than IGF-1 at a dose mediating a comparable hypoglycemic effect because glucose metabolism activity by insulin is approximately 30 times stronger than that of IGF-1. Increasing the dose of insulin to the level equipotent to IGF-1 in promoting the differential regulation of Bcl-xL and Bax could be effective in preventing paraplegia but may cause lethal hypoglycemia. It is thus proposed that the novel IGF-1 therapy, but not a conventional glucose-insulin therapy, is required for protecting motor neuron cells from ischemic spinal cord injury.
It is now evident that the quantitative ratio of antiapoptotic to proapoptotic Bcl-2 family proteins is crucial in determining life and death of the cell. In the present study Bcl-2 was not detected immunohistochemically in motor neuron cells after any treatment modality, suggesting that $\mathrm{Bcl}-2$ is not an inducible major antiapoptotic protein after the IGF-1 treatment in motor neuron cells. In contrast, Bax and Bcl-xL expression was altered dramatically after ischemia and the IGF-1 treatment but in an opposite way, suggesting the importance of these $\mathrm{Bcl}-2$ family proteins in regulating motor neuron cell survival and death after spinal cord ischemia. Although the present study does not provide a causal relationship between the differential regulation of Bcl-2 family proteins and spinal cord protection, the putative roles of Bcl-2 family proteins are consistent with the hypothesis that up-regulation of Bcl-xL and down-regulation of Bax by treatment with IGF-1 could promote the sur- 


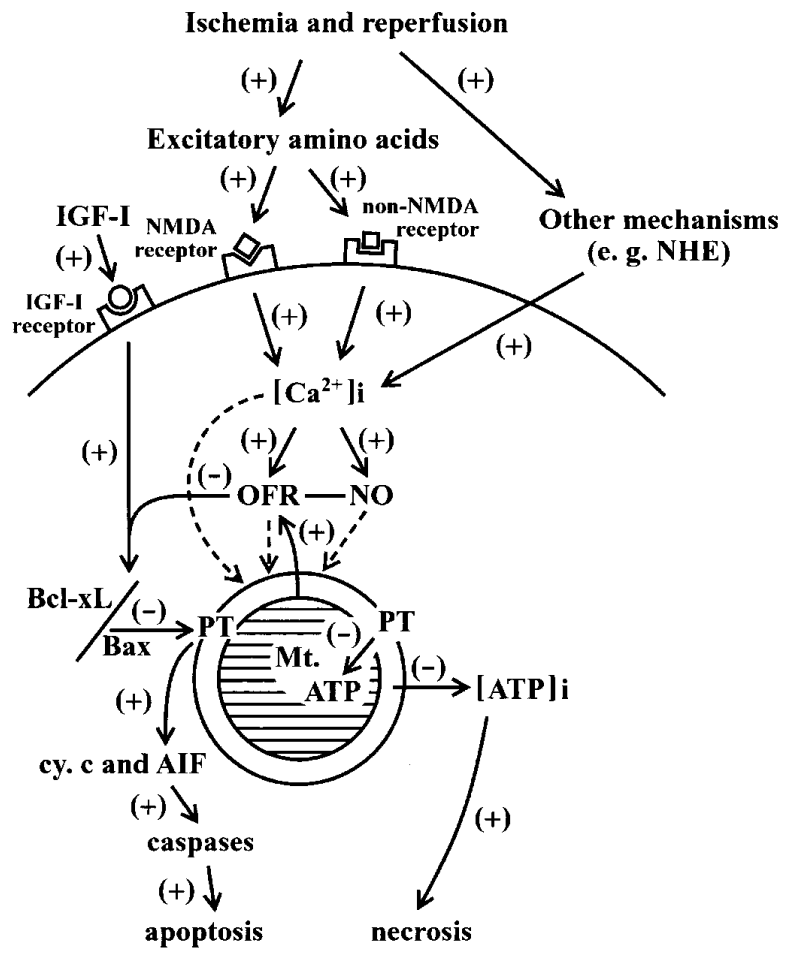

Figure 5. Proposed mechanism of IGF-I-induced spinal cord protection. $(+)$ and (-) indicate stimulation and inhibition, respectively. Dashed line indicates assault on mitochondria. NMDA, $\mathbf{N}$ methyl-D-aspartate; $\mathrm{NHE}, \mathrm{Na}^{+} / \mathrm{H}^{+}$exchange; $\mathrm{Mt}$, mitochondria; $\mathrm{cy}$. c, cytochrome c; AIF, apoptosis-inducing factor.

vival of motor neuron cells after ischemic spinal cord injury. Figure 5 depicts the proposed mechanism of IGF1-induced spinal cord protection. Spinal cord ischemia and reperfusion increase excitatory amino acids in the proximity of neuronal cell membranes that stimulates $N$-methyl-Daspartate and non- $N$-methyl-D-aspartate receptors. These receptors, ${ }^{26}$ in conjunction with other mechanisms, such as $\mathrm{Na}^{+} / \mathrm{H}^{+}$exchange-mediated ${ }^{27}$ increase in intracellular $\mathrm{Ca}^{2+}$, stimulates the synthesis of oxygen-derived free radicals and nitric oxide. ${ }^{28,29}$ The increase in intracellular $\mathrm{Ca}^{2+}$, oxygen-derived free radicals, and nitric oxide opens the mitochondrial permeability transition pore. Permeability transition pore is a large-conductance, cyclosporine (INN: ciclosporin)-inhibitable channel in the inner membrane of mitochondria. ${ }^{30}$ Permeability transition-pore opening causes dissipation of $\mathrm{H}^{+}$gradient across the membrane. The loss of electrochemical gradient results in uncoupling of the respiratory chain and subsequent abrogation of adenosine triphosphate synthesis by means of $\mathrm{F}_{0}-\mathrm{F}_{1}$ adenosine triphosphatase. Depriving the cell of adenosine triphosphate is a primary step for necrosis. Permeability transition-pore opening, on the other hand, is associated with the release of cytochrome $\mathrm{c}$ and apoptosis-inducing factor from mitochondria. ${ }^{31}$ Cytochrome $\mathrm{c}$ released into cytosol can activate a cysteine protease (caspase) cascade, leading to apoptosis in the presence of Apaf-1 and deoxyadenosine triphosphate. ${ }^{32} \mathrm{Bcl}-2$ family proteins, which reside abundantly in the outer membrane of mitochondria, are thought to regulate permeability transition-pore opening. ${ }^{31-34} \mathrm{Bcl}-$ $\mathrm{xL}$ interferes with mitochondrial permeability transitionpore opening, as well as with the release of cytochrome c and apoptosis-inducing factor. ${ }^{35} \mathrm{Bax}$, on the contrary, accelerates cytochrome $\mathrm{c}$ release by interacting with Bcl$\mathrm{xL} .{ }^{36}$ Thus, Bcl-xL and Bax are critically involved in both necrosis and apoptosis, and these two morphologically distinct forms of cell death could be prevented simultaneously by increasing the quantitative ratio of $\mathrm{Bcl}-\mathrm{xL}$ and $\mathrm{Bax}$ in mitochondria. Ischemia- and reperfusion-induced increase in oxygen-derived free radicals and nitric oxide synthesis are known to up-regulate Bax expression. ${ }^{37,38}$ On the contrary, IGF-1 treatment promotes up-regulation of Bcl-xL and down-regulation of Bax, ${ }^{39,40}$ which could block all the death signals arising from mitochondria downstream of increases in intracellular $\mathrm{Ca}^{2+}$, oxygen-derived free radicals, and nitric oxide. Indeed, in our study serial sections of the spinal cord segment subjected to ischemia demonstrated that Bcl-xL-negative and Bax-positive motor neuron cells underwent necrotic, as well as apoptotic, changes.

The loss of hind-limb motor function occurred within 6 hours after the operation in a considerable number of control rabbits and those treated with insulin. This finding indicates that motor neuron dysfunction induced by ischemia and reperfusion is not always mediated by delayed onset of neuronal cell death but is also caused by acute neuronal cell damage. Therefore, it is reasonable to assume that a part of the benefit in spinal cord protection conferred by IGF-1 may be unrelated to enhanced expression of Bcl-xL because the synthesis of Bcl-xL protein may require at least hours after the IGF-1 treatment. In this regard, our recent study ${ }^{41}$ with the isolated and perfused rat heart model demonstrated that IGF-1 treatment at the moment of reperfusion was effective in improving left ventricular function and in inhibiting acute necrotic cardiomyocyte cell death. Thus, the mechanism of prevention of acute onset of neuronal cell injury by IGF-1 after spinal cord ischemia remains to be investigated.

In conclusion, bolus intravenous administration 30 minutes before spinal cord ischemia of IGF-1 at a dose equipotent to insulin in reducing blood glucose level conferred significant benefit in preventing paraplegia in the rabbit model. Although the exact mechanism of neuronal cell protection by IGF-1 remains to be clarified, circumstantial evidence that the IGF-1 treatment enhanced the expression of antiapoptotic Bcl-xL protein and inhibited the expression of proapoptotic Bax protein suggests that the differential regulation of these death-regulatory proteins may be involved in the mechanism of protection against delayed onset of neuronal cell death and development of paraplegia. 
We are grateful for excellent technical assistance by Aya Kobayashi.

\section{References}

1. Livesay JJ, Cooley DA, Ventemiglia RA, Montero CG, Warrian RK, Brown DM, et al. Surgical experience in descending thoracic aneurysmectomy with and without adjuncts to avoid ischemia. Ann Thorac Surg. 1985;39:37-46.

2. Crawford ES, Crawford JL, Safi HJ, Coselli JS, Hess KR, Brooks B, et al. Thoracoabdominal aortic aneurysms: preoperative and intraoperative factors determining immediate and long-term results of operations in 605 patients. J Vasc Surg. 1986;3:389-404.

3. Gharagozloo F, Larson J, Dausmann MJ, Neville RF Jr, Gomes MN. Spinal cord protection during surgical procedures on the descending thoracic and thoracoabdominal aorta: review of current techniques. Chest. 1996;109:799-809.

4. Zivin JA, De Girolami U. Spinal cord infarction: a highly reproducible stroke model. Stroke. 1980;11:200-2.

5. Jacobs TP, Shohami E, Baze W, Burgard E, Gunderson C, Hallenbeck $\mathrm{JM}$, et al. Deteriorating stroke model: histopathology, edema, and eicosanoid change following spinal cord ischemia in rabbits. Stroke. 1987;18:741-50

6. Moore WM Jr, Hollier LH. The influence of severity of spinal cord ischemia in the etiology of delayed-onset paraplegia. Ann Surg. 1991;213:427-32.

7. Mackey ME, Wu Y, Hu R, DeMaro JA, Jacquin MF, Kanellopoulos GK, et al. Cell death suggestive of apoptosis after spinal cord ischemia in rabbits. Stroke. 1997;28:2012-7.

8. Lang-Lazdunski L, Heurteaux C, Vaillant N, Widmann C, Lazdunski M. Riluzole prevents ischemic spinal cord injury caused by aortic crossclamping. J Thorac Cardiovasc Surg. 1999;117:881-9.

9. Miyashita T, Krajewski S, Krajewska M, Wang HG, Lin HK, Liebermann DA, et al. Tumor suppressor p53 is a regulator of bcl-2 and bax gene expression in vitro and in vivo. Oncogene. 1994;9:1799-805.

10. Yang J, Liu X, Bhalla K, Kim CN, Ibrado AM, Cai J, et al. Prevention of apoptosis by Bcl-2: release of cytochrome $\mathrm{c}$ from mitochondria blocked. Science. 1997;275:1129-32.

11. Narita M, Shimizu S, Ito T, Chittenden T, Lutz RJ, Matsuda H, et al. Bax interacts with the permeability transition pore to induce permeability transition and cytochrome c release in isolated mitochondria. Proc Natl Acad Sci U S A. 1998;95:14681-6.

12. Misao J, Hayakawa $Y$, Ohno M, Kato S, Fujiwara T, Fujiwara $H$. Expression of bcl-2 protein, an inhibitor of apoptosis, and Bax, an accelerator of apoptosis, in ventricular myocytes of human hearts with myocardial infarction. Circulation. 1996;94:1506-12.

13. Cheng W, Kajstura J, Nitahara KA, Li B, Reiss K, Liu Y, et al. Programmed myocyte cell death affects the viable myocardium after infarction in rats. Exp Cell Res. 1996;226:316-27.

14. Martinou JC, Dubois-Dauphin M, Staple JK, Rodriguez I, Frankowski $\mathrm{H}$, Missotten M, et al. Overexpression of Bcl-2 in transgenic mice protects neurons from naturally occurring cell death and experimental ischemia. Neuron. 1994;13:1017-30.

15. Isenmann S, Stoll G, Schroeter M, Krajewski S, Reed JC, Bahr M. Differential regulation of Bax, Bcl-2, and Bcl-X proteins in focal cortical ischemia in the rat. Brain Pathol. 1998;8:49-63.

16. Rinderknecht E, Humbel RE. The amino acid sequence of insulin-like growth factor-1 and its structural homology with proinsulin. J Biol Chem. 1978;253:2769-76.

17. Froesch ER, Schmid C, Ashwander J, Zapf J. Actions of insulin-like growth factors. Аnпи Rev Physiol. 1985;47:443-67.

18. Tagami M, Ikeda K, Nara Y, Fujino H, Kubota A, Numano F, et al. Insulin-like growth factor- 1 attenuates apoptosis in hipocampal neurons caused by cerebral ischemia and reperfusion in stroke prone of spontaneously hypertensive rats. Lab Invest. 1997;76:613-7.

19. Li Q, Li B, Wang X, Leri A, Jana KP, Liu Y, et al. Overexpression of insulin-like growth factor-1 in mice protects from myocyte death after infarction, attenuating ventricular dilation, wall stress, and cardiac hypertrophy. J Clin Invest. 1997;100:1991-9.
20. Parrizas M, Leroith D. Insulin-like growth factor-1 inhibition of apoptosis is associated with increased expression of the bcl-xL gene product. Endocrinology. 1997;138:1355-8.

21. Minshall C, Arkins S, Straza J, Conners J, Dantzer R, Freund GG, et al. IL-4 and insulin-like growth factor-I inhibit the decline in Bcl-2 and promote the survival of IL-3-deprived myeloid progenitors. $J$ Immunol. 1997;159:1225-32.

22. Wang L, Ma W, Markovich R, Lee WL, Wang PH. Insulin-like growth factor I modulates induction of apoptotic signaling in $\mathrm{H} 9 \mathrm{C} 2$ cardiac muscle cells. Endocrinology. 1998;139:1354-60.

23. Tarlov IM. Acute spinal cord compression paralysis. J Neurosurg. 1972;36:10-20.

24. Vekrellis K, McCarthy MJ, Watson A, Whitfield J, Rubin LL, Ham J. Bax promotes neuronal cell death and is downregulated during the development of the nervous system. Development. 1997;124:1239-49.

25. Parsadanian AS, Cheng Y, Keller-Peck CR, Holtzman DM, Snider WD. Bcl-xL is an antiapoptotic regulator for postnatal CNS neurons. J Neurosci. 1998;18:1009-19.

26. Choi DW, Maulucci-Gedde M, Kriegstein AR. Glutamate neurotoxicity in cortical cell culture. J Neurosci. 1987;7:357-68.

27. Kuribayashi Y, Itoh N, Kitano M, Ohashi N. Cerebroprotective properties of SM-20220, a potent $\mathrm{Na}(+) / \mathrm{H}(+)$ exchange inhibitor, in transient cerebral ischemia in rats. Eur J Pharmacol. 1999;383:163-8.

28. Dykens JA. Isolated cerebral and cerebellar mitochondria produce free radicals when exposed to elevated $\mathrm{Ca}^{2+}$ and $\mathrm{Na}^{+}$: implications for neurodegeneration. J Neurochem. 1994;63:584-91.

29. Delgado-Esteban M, Almeida A, Bolanos JP. D-Glucose prevents glutathione oxidation and mitochondrial damage after glutamate receptor stimulation in rat cortical primary neurons. $J$ Neurochem. 2000;75:1618-24.

30. Zamzami N, Susin SA, Marchetti P, Hirsch T, Gomez-Monterrey I, Castedo M, et al. Mitochondrial control of nuclear apoptosis. $J$ Exp Med. 1996;183:1533-44.

31. Marzo I, Brenner C, Zamzami N, Susan SA, Beutner G, Brdiczka D, et al. The permeability transition pore complex: a target for apoptosis regulation by caspases and Bcl-2-related proteins. J Exp Med. 1998; 187:1261-71.

32. Zou H, Henzel WJ, Liu X, Lutschg A, Wang X. Apaf-1, a human protein homologous to C. elegans CED-4, participates in cytochrome cdependent activation of caspase-3. Cell. 1997;90:405-13.

33. Reed JC, Jurgensmeier JM, Matsuyama S. Bcl-2 family proteins and mitochondria. Biochim Biophys Acta. 1998;1366:127-37.

34. Zamzani N, Brenner C, Marzo I, Susan SA, Kroemer G. Subcellular and submitochondrial mode of action of Bcl-2-like oncoproteins. Oncogene. 1998;16:2265-82.

35. Kharbanda S, Pandey P, Schofield L, Israels S, Roncinske R, Yoshida $\mathrm{K}$, et al. Role for Bcl-xL as an inhibitor of cytosolic cytochrome $\mathrm{c}$ accumulation in DNA damage-induced apoptosis. Proc Natl Acad Sci U S A. 1997;94:6939-42.

36. Sedlak TW, Oltvai ZN, Yang E, Wang K, Boise LH, Thompson CB, et al. Multiple Bcl-2 family members demonstrate selective dimerization with Bax. Proc Natl Acad Sci U S A. 1995;92:7834-8.

37. Zhou LJ, Zhu XZ. Reactive oxygen species-induced apoptosis in PC12 cells and protective effect of bilobalide. J Pharmacol Exp Ther. 2000;293:982-8

38. Matsuzaki H, Tamatani M, Mitsuda N, Namikawa K, Kiyama H, Miyake S, et al. Activation of Akt kinase inhibits apoptosis and changes in Bcl-2 and Bax expression induced by nitric oxide in primary hippocampal neurons. J Neurochem. 1999;73:2037-46.

39. Wang L, Ma W, Markovich R, Chen JW, Wang PH. Regulation of cardiomyocyte apoptosis signaling by insulin-like growth factor I. Circ Res. 1998;83:516-22.

40. Yamamura T, Otani H, Nakao Y, Hattori R, Osako M, Imamura H. IGF-I differentially regulates Bcl-xL and Bax and confers myocardial protection in rat heart. Am J Physiol. 2001;280:H1191-200.

41. Otani H, Yamamura T, Nakao Y, Hattori R, Kawaguchi H, Osako M, et al. Insulin-like growth factor-I improves recovery of cardiac performance during reperfusion in isolated rat heart by a wortmannin-sensitive mechanism. J Cardiovasc Pharmacol. 2000;35:275-81. 